\title{
Anatomy of the Dorsalis Pedis Artery
}

\author{
Anatomía de la Arteria Dorsal del Pie
}

\author{
J. S. Luckrajh ${ }^{1}$; L. Lazarus ${ }^{1}$; N. Naidoo ${ }^{2}$; C. Rennie $^{1}$ \& K. S. Satyapal ${ }^{1}$
}

LUCKRAJH, J. S.; LAZARUS, L.; NAIDOO, N.; RENNIE, C. \& SATYAPAL, K. S. Anatomy of the dorsalis pedis artery. Int. J. Morphol., 36(2):730-736, 2018.

SUMMARY: The dorsalis pedis artery (DPA) is the largest blood vessel distal to the ankle joint. It is the continuation of the anterior tibial artery (ATA) and runs along the dorsum of the foot until the $1^{\text {st }}$ intermetatarsal space. The DPA gives rise to five branches, viz. medial tarsal, lateral tarsal, arcuate, deep plantar and dorsal metatarsal arteries. Given the vast blood supply provided by the DPA, in the current era of microvascular surgery, the anatomy of the DPA is of increasing interest to anatomists, surgeons and angiographers. The aim of this study was to outline the course, origin, branching patterns and possible variations of the DPA. The present study included the dissection of forty $(n=40)$ cadaveric specimens of the lower limb region (Left: 25; Right: 15). The origin, course and branching patterns of the artery were studied. These morphological parameters were further analysed with regard to laterality to determine if a correlation existed. The Pearson Chi-square test was employed and a $p$ value of less than 0.05 was deemed statistically significant. Although the DPA was present in $97.5 \%$ of cases, it followed the standard anatomical description in only $42.5 \%$ of cases. The DPA originated from the peroneal artery in $5 \%$ of cases. In $25 \%$ of cases, DPA deviated laterally. Variation in the branching pattern of the DPA, which was recorded in $50 \%$ of cases, was further classified according Types 1 to 6 . The findings of this study correlated closely with most previous studies. However, the incidence of lateral deviation of the DPA was higher in this study as well as the incidence of Type 1 variation in branching pattern. Additionally, this study proposes a novel variation in branching pattern which has been termed Type 6, which displays a recurrent branch of the Type 5 variation. The DPA has an important role in a clinical setting since the DPA flap is employed in reconstructive surgeries and peripheral circulation may be assessed by the palpation of the DPA pulse. Therefore, a thorough understanding of the anatomy of the DPA is of prime importance to podiatrists, surgeons, anatomists and angiographers.

KEY WORDS: Dorsalis Pedis Artery; Arterial Anatomy; Dorsalis Pedis Flap; Dorsalis Pedis Pulse.

\section{INTRODUCTION}

As the largest artery distal to the ankle joint, the dorsalis pedis artery (DPA) is the chief artery of the foot (Standring et al., 2016). The DPA is the downward continuation of the anterior tibial artery (ATA) at the level of the ankle joint and courses obliquely along the dorsum of the foot to reach the $1^{\text {st }}$ intermetatarsal space (Standring et al.). At this point, the DPA passes inferiorly between the two heads of the $1^{\text {st }}$ interosseous muscle to complete the plantar arterial arch (Kelikian \& Sarrafian, 2011; Standring et al.).

Along its course, the DPA gives rise to the medial tarsal, lateral tarsal, arcuate, deep plantar and $1^{\text {st }}$ dorsal metatarsal arteries. This standard anatomic description has been recorded by many authors (Vazquez et al., 2006; Kelikian \& Sarrafian; Moore et al., 2014; Standring et al.). However, Standring et al. noted the variant nature of the DPA with regard to its course, origin and branching pattern. Results of recent studies by Vijayalakshmi et al. (2011), Kulkarni \& Ramesh (2012), Rajeshwari et al. (2013) and Kumari \& Bharti (2016) corroborated this statement. These authors have only identified the standard anatomy of the DPA in $56 \%, 15.2 \%, 55 \%$ and $73 \%$ of cases, respectively.

El-Saeed et al. (2008) recorded a variation in the origin of the DPA where the peroneal artery gave rise to the DPA. This variation has been recorded by many authors (Vijayalakshmi et al.; Kulkarni \& Ramesh; Rajeshwari et al.; Shetty et al., 2013; Kumari \& Bharti; Cheung et al., 2017).

Variation in the course of the DPA, such as a lateral deviation of it has been recorded by Vijayalakshmi et al., Awari \& Vatsalaswamy (2016), Kumari \& Bharti and Vengadesan \& Pushpalatha (2017).

\footnotetext{
${ }^{1}$ Discipline of Clinical Anatomy, School of Laboratory Medicine and Medical Science, College of Health Sciences, University of KwaZulu-Natal, Westville Campus, Private Bag X54001, Durban, 4000, South Africa.

${ }^{2}$ College of Medicine, Mohammed Bin Rashid University of Medicine and Health Sciences, Dubai Healthcare City, United Arab Emirates.
} 
Furthermore, variations in the standard branching pattern of the DPA have been recorded by El-Saeed et al., Kulkarni \& Ramesh and Kumari \& Bharti. Knowledge of the branching pattern of the DPA is invaluable to the surgeon during preoperative vascular mapping of the foot (Chow et $a l ., 2005)$. It may prevent iatrogenic injury and increase the success rate of podiatric surgery.

Myocutaneous flaps of the DPA have become an integral component in reconstructive surgeries of the hand, eye socket and pharyngocutaneous fistulae (Mamatha et al., 2014; Kulkarni \& Ramesh). The viability of the flap is solely dependent on the degree of vascularity of this vessel (Kulkarni \& Ramesh). An additional clinical implication of the DPA is the use of the DPA pulse for the assessment of peripheral arterial perfusion (Mowlavi et al., 2002; Vijayalakshmi et al.; Kulkarni \& Ramesh). Presence of the DPA pulse rules out circulatory disease, whereas its absence may be indicative of occluded vessels.

This study aimed to investigate the anatomy of the DPA by outlining its origin, course and branching patterns.

\section{MATERIAL AND METHOD}

A sample of forty adult cadaveric feet $(n=40)$ were dissected at the Discipline of Clinical Anatomy, University of KwaZulu-Natal in accordance with the National Health Act no 61 of 2003. Ethical clearance was obtained from the Biomedical Research Ethics Committee of the University of KwaZulu-Natal (BE302/17).

All specimens with previous ankle surgery, fractures, dislocations or any other macroscopic evidence of pathology were excluded from this study.

The dissection procedure employed an anterior approach to the dorsum of the foot (Tank \& Grant, 2012). The skin of the dorsum of the foot was removed and fascia reflected to expose the tendons of the tibialis anterior, extensor hallucis longus (EHL) and extensor digitorum longus (EDL) muscles. The DPA was then identified in a neurovascular bundle, between the proximal part of the tendons of the EHL and EDL (Tank \& Grant).

This was a descriptive study where the frequencies of the origin, course and branching pattern of the DPA were recorded and these parameters were then correlated with laterality. Due to the absence of detailed cadaver records; the age, sex and population group of the specimens were not documented.

The statistical analysis was performed using the IBM Statistical Package for Social Sciences (SPSS), version 21.0. The Pearson Chi-square test evaluated the level of statistical significance (if any), with a $p$ value of less than 0.05 deemed to be statistically significant.

\section{RESULTS}

Incidence. The DPA was identified in $97.5 \%$ of cases (Right: $35 \%$; Left: $62.5 \%$ ) (Table I).

Course. The DPA was found to pass from the midpoint between the malleoli to the proximal end of the $1^{\text {st }}$ intermetatarsal space in $42.5 \%$ of the sample size (Fig. 1, Table I). In addition, the standard anatomical course, where the DPA passed from the midpoint of the bimalleolar axis to the $1^{\text {st }}$ intermetatarsal space, was also exhibited in $12.5 \%$ and $30 \%$ of feet on the right and left sides, respectively (Table I).

The variant course of the DPA, where it crossed the lateral malleolus and passed forward along the lateral dorsum of the foot to reach the proximal end of the $1^{\text {st }}$ intermetatarsal space, was recorded in $25 \%$ of cases (Right: $7.5 \%$; Left: $17.5 \%$ ) (Fig. 2, Table I).

Origin. The DPA arose from the peroneal artery and passed to the $1^{\text {st }}$ intermetatarsal space in $5 \%$ of cases (Right: 2.5 $\%$; Left: $2.5 \%$ ) (Fig. 3, Table I).

Branching Pattern. The anomalous course of the DPA was observed in $50 \%$ of cases (Table I). These variations were classified into 6 Types:

Table I. Incidence of the Morphological Parameters of the DPA «(\%)»

\begin{tabular}{lcccccc}
\hline \multicolumn{1}{c}{ Parameter } & $\begin{array}{c}\text { Presence } \\
(\%)\end{array}$ & $\begin{array}{c}\text { Standard Anatomical } \\
\text { Course (\%) }\end{array}$ & $\begin{array}{c}\text { Anomalous } \\
\text { Course (\%) }\end{array}$ & $\begin{array}{c}\text { Anomalous } \\
\text { Origin (\%) }\end{array}$ & $\begin{array}{c}\text { Anomalous Branching } \\
\text { pattern (\%) }\end{array}$ \\
\hline Standard & & 97.5 & 42.5 & 25 & 5 & 50 \\
Laterality & Right & 35 & 12.5 & 7.5 & 2.5 & 20 \\
& Left & 62.5 & 30 & 17.5 & 2.5 & 30 \\
P value & & 0.191 & 0.364 & 0.572 & 0.708 & 0.744 \\
\hline
\end{tabular}




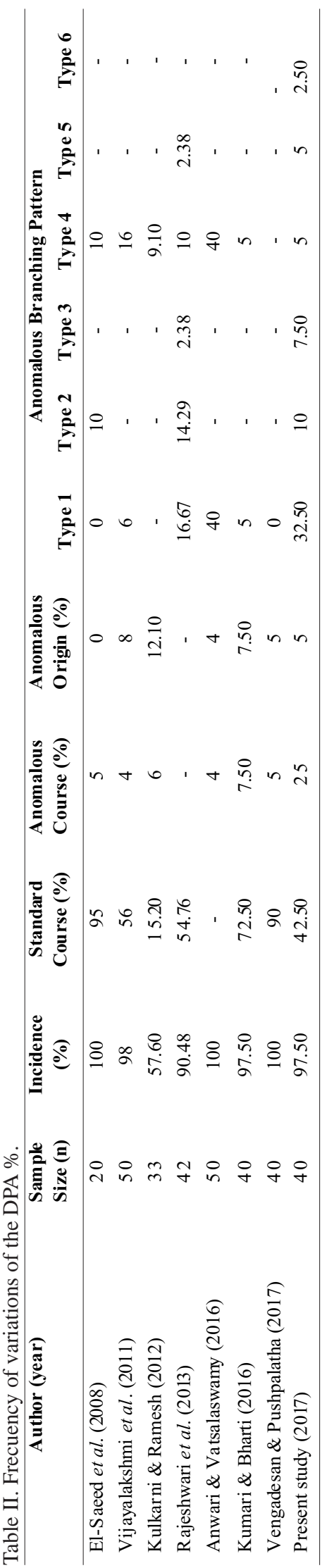

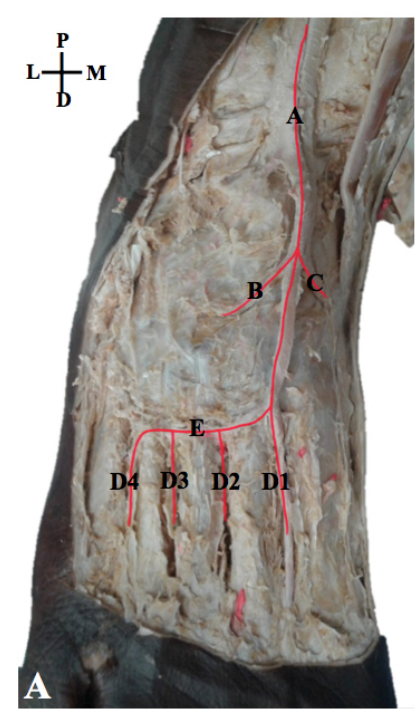

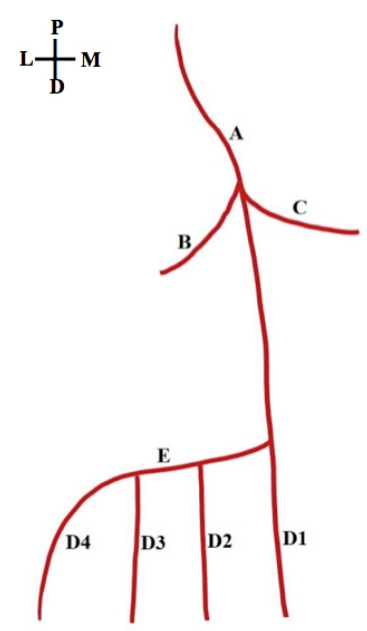

B
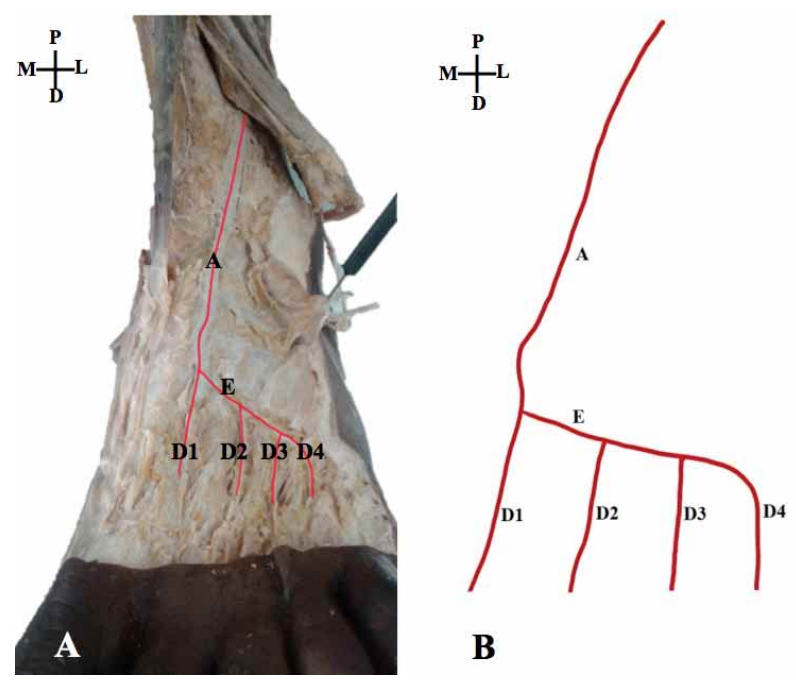

B

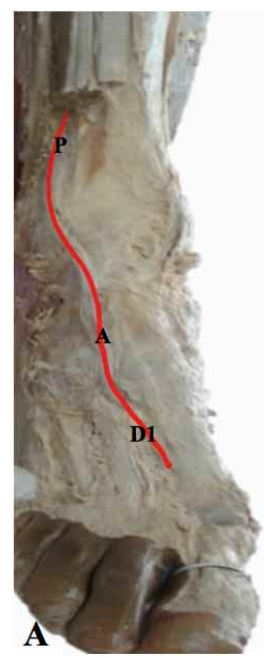

Fig. 1. Standard course of the DPA: Dissection (A) and corresponding schematic diagram (B) (Anterior view; right foot).

Key: A- Dorsalis pedis artery; B- lateral tarsal artery; C- Medial tarsal artery; D- Distal; D1- $1^{\text {st }}$ dorsal metatarsal artery; D2- $2^{\text {nd }}$ dorsal metatarsal artery; D3$3^{\text {rd }}$ dorsal metatarsal artery; D4- $4^{\text {th }}$ dorsal metatarsal artery; E- Arcuate artery; LLateral; M- Medial; PProximal

Fig. 2. Anomalous course of the DPA: Dissection (A) and corresponding schematic diagram (B) (Anterior view; left foot).

Key: A- Dorsalis pedis artery; D- Distal; D1- $1^{\text {st }}$ dorsal metatarsal artery; D2- $2^{\text {nd }}$ dorsal metatarsal artery; D3$3^{\text {rd }}$ dorsal metatarsal artery; D4- $4^{\text {th }}$ dorsal metatarsal artery; E- Arcuate artery; LLateral; M- Medial; PProximal

Fig. 3. Anomalous origin of the DPA: Dissection (A) and corresponding schematic diagram (B) (Anterior view; right foot).

Key: A- Dorsalis pedis artery, D1- $1^{\text {st }}$ dorsal metatarsal artery; D- Distal; L- Lateral; M- Medial; PPeroneal artery; PRProximal 

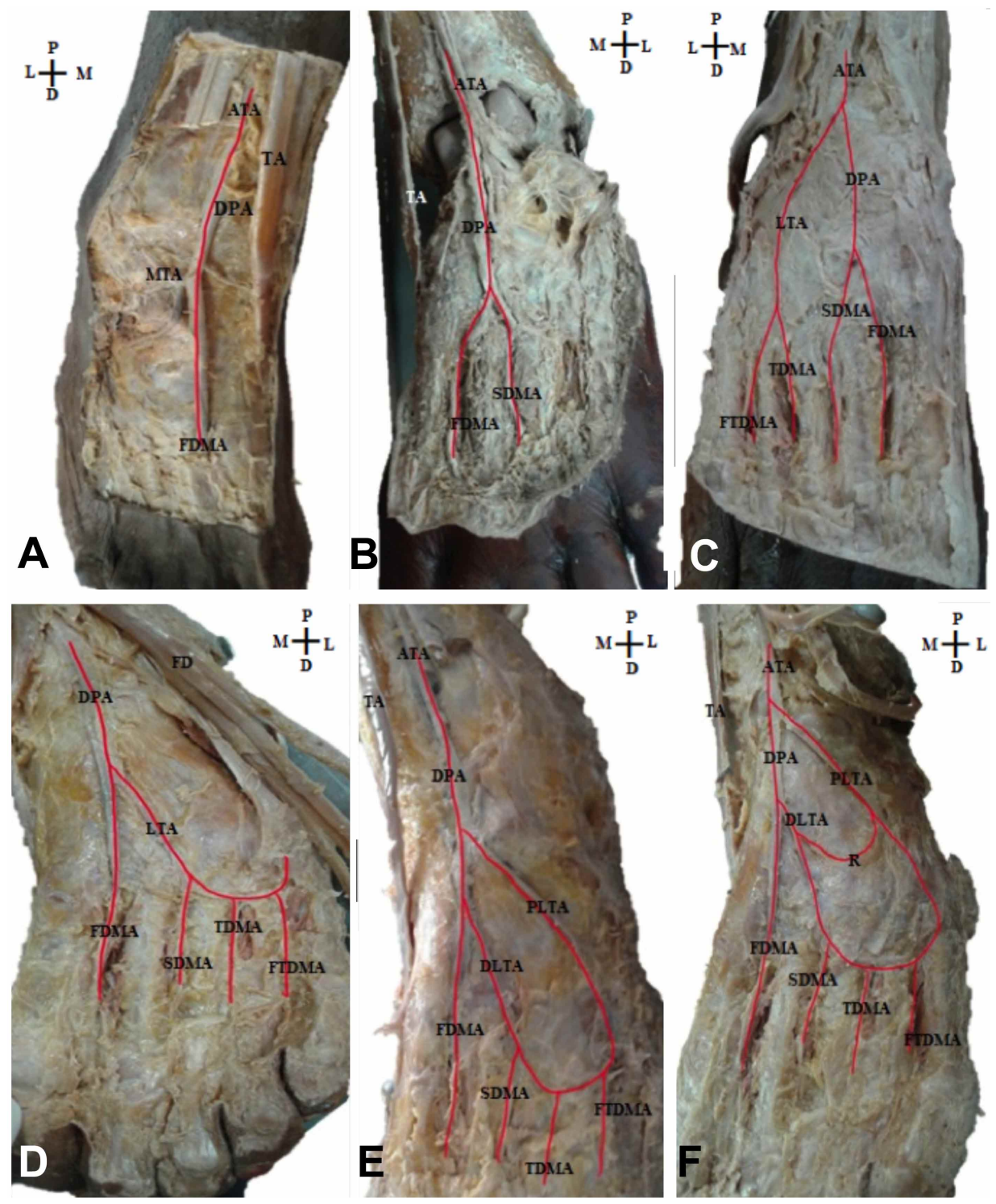

Fig. 4. Variation in branching pattern. A: Type 1; B: Type 2; C: Type 3; D: Type 4; E: Type 5; F: Type 6. ATA- Anterior Tibial Artery; D- Distal; DPA- Dorsalis Pedis Artery; DLTA- Distal Dorsal Metatarsal Artery; FDMA- First Dorsal Metatarsal Artery; FTDMAFourth Dorsal Metatarsal Artery; LLateral; M- Medial; MTA- Medial Tarsal Artery; P- Proximal; PLTAProximal Dorsal Metatarsal Artery; R- Recurrent Branch; SDMASecond Dorsal Metatarsal Artery; TA- Tendon Of Tibialis Anterior; TDMA- Third Dorsal Metatarsal Artery
Type 1 . The arcuate artery was absent in $32.5 \%$ of cases (Fig. 4a).

Type 2 . The DPA gave rise to the $1^{\text {st }}$ and $2^{\text {nd }}$ DMA in $10 \%$ of cases (Fig. 4b).

Type 3. The DPA gave rise to the $1^{\text {st }}$ and $2^{\text {nd }}$ DMA and the LTA gave rise to the $3^{\text {rd }}$ and 4 th DMA in $7.5 \%$ of specimens (Fig. 4c).

Type 4 . The $2^{\text {nd }}, 3^{\text {rd }}$ and $4^{\text {th }}$ DMA arose from a large LTA in 5 $\%$ of cases (Fig. $4 d$ ).

Type 5. The "U-shaped loop" was found in $5 \%$ of specimens (Fig. 4e).
Type 6. The "U-shaped loop" with a recurrent branch occurred in $2.5 \%$ of cases (Fig. 4f).

No statistically significant differences were recorded for the comparison of the morphological parameters with laterality.

\section{DISCUSSION}

Upon intricate dissection of 40 cadaveric specimens, the DPA was present in $97.5 \%$ of cases (Table I). In 2012, Kulkarni \& Ramesh found the DPA in 57.6\% of cases which is significantly lower than the result of 
the present study (Table II). On the other hand, the findings of Rajeshwari et al. and Kumari \& Bharti were very similar to this study with an incidence of $90.48 \%$ and 97.5 $\%$, respectively (Table II). The absence of the DPA may result in clinical misdiagnosis as an indicator of peripheral arterial perfusion, since the absence of the DPA pulse may instead be interpreted as an occluded vessel (Kulkarni \& Ramesh). Therefore, Vijayalakshmi et al. suggested confirmation by angiography before treatment is administered.

The present study recorded the standard course of the DPA as arising from the ATA, at the level of the ankle joint, situated in the midline of the ankle. The vessel then passed obliquely along the dorsum of the foot to reach the first intermetatarsal space (Fig. 1). The DPA followed this standard course in $42.5 \%$ of cases in this study (Fig. 1, Table I). Although, slightly decreased in prevalence, the results of this study were similar to that of Vijayalakshmi et al. and Rajeshwari et al. who noted incidences of $56 \%$ and $54.76 \%$, respectively (Table II). On the other hand, Vengadesan \& Pushpalatha documented a much higher frequency in the prevalence of the standard anatomical course of the DPA of $90 \%$ (Table II).

This study recorded a lateral deviation in the course of the DPA in $25 \%$ of cases (Fig. 2, Table I). However, in previous studies this was found with consistently lesser frequencies as Vijayalakshmi et al., Awari \& Vatsalaswamy and Vengadesan \& Pushpalatha recorded it in $4 \%, 4 \%$ and $5 \%$ of cases, respectively (Table II).

The DPA pulse is commonly used in a clinical setting for the evaluation of peripheral circulation. Mowlavi et al. suggested the dorsal most prominence of the navicular bone as a bony landmark for the palpation of the DPA pulse. However, the present study found cases where the DPA was deviated laterally. In these cases palpation at this landmark may indicate absence of pulse and disease, whereas it is an anatomical variation. This further emphasises the need for clinicians to be aware of such a variation and the frequency with which it occurs.

The present study concurred with the findings of Awari \& Vatsalaswamy and Vengadesan \& Pushpalatha as the DPA arose from the peroneal artery in $5 \%$ of specimens only (Fig. 3, Table I). Furthermore, Shetty et al. stated that in cases where the ATA is congenitally absent or hypoplastic, the peroneal artery directly supplied the distal arterial distribution area of the ATA.

Khaki et al. (2006) defined anatomical variation as the normal range in topography and morphology of the body structures. Cheung et al. suggested that as blood vessels are formed during the 3rd and 4th weeks of embryonic development, abnormal fusions or the regression and divergence of some vessels may result in variable arterial distribution.

In $50 \%$ of specimens in this study, variations in branching patterns of the DPA were observed (Table I). These were classified as:

Type 1: As the DPA coursed along the dorsum of the foot, it failed to give rise to the arcuate artery. This study found the arcuate artery to be completely absent in 32.5 $\%$ of cases (Fig. 4a). Similarly, Vengadesan \& Pushpalatha recorded this in $40 \%$; however, Rajeshwari et al. only found this in $16.67 \%$ of cases (Table II). Mamatha et al. stated that in the absence of the arcuate artery, the LTA and branches of the plantar arterial arch supply the $2^{\text {nd }}$ to $4^{\text {th }}$ metatarsal spaces (Table II). The absence of the arcuate artery may be a contraindication of DPA flap surgery as the viability of the flap is solely dependent on the vascularity of the DPA (Kulkarni \& Ramesh). The absence of the arcuate artery will imply the absence of the $2^{\text {nd }}-4^{\text {th }}$ DMA as well thus compromising the viability of the flap (Kulkarni \& Ramesh). Consequently, knowledge of the incidence of Type 1 variation is essential to the foot surgeon (Kulkarni \& Ramesh).

Type 2: Superior to the base of the second metatarsal, the DPA gave rise to $1^{\text {st }}$ and $2^{\text {nd }}$ DMA only. This occurred in $10 \%$ of cases in the present investigation and is the same as the result of El-Saeed et al. (Fig. 4b, Table II). In 2013, Rajeshwari et al. recorded this with a slightly higher incidence of $14.29 \%$ (Table II). It is hypothesized that the $3^{\text {rd }}$ and $4^{\text {th }}$ DMA may arise from the plantar arterial arch in this case (Mamatha et al.).

Type 3: The DPA gave rise to the $1^{\text {st }}$ and $2^{\text {nd }}$ DMA while the $3^{\text {rd }}$ and $4^{\text {th }}$ DMA arose from the LTA. This only occurred in $7.5 \%$ of specimens in the present study and Rajeshwari et al. recorded it in $2.38 \%$ of specimens (Fig. 4c, Table II).

Type 4: The $2^{\text {nd }}, 3^{\text {rd }}$ and $4^{\text {th }}$ DMA arose from a large LTA, while the DPA only gave rise to the 1st DMA at the level of the base of the $1^{\text {st }}$ intermetatarsal space (Fig. 4d). This occurred in $5 \%$ of cases and is similar to the findings of El-Saeed et al. (10\%), Kulkarni \& Ramesh (9.1\%), Rajeshwari et al. (10\%) and Kumari \& Bharti (5\%) (Table II). Conversely, Awari \& Vatsalaswamy found this with a higher frequency in $40 \%$ of specimens (Table II).

Type 5: The U-shaped loop variation was found in $5 \%$ 
of specimens (Fig. 4e). In these cases, a proximal and distal LTA was present and both ran obliquely and laterally to join and form a loop. The $2^{\text {nd }}, 3^{\text {rd }}$ and $4^{\text {th }}$ DMA arose from this loop and the DPA course to the $1^{\text {st }}$ intermetatarsal space and gave rise to the $1^{\text {st }}$ DMA. This variation is rare, as Rajeshwari et al. only observed this in $2.8 \%$ of cases (Table II).

Type 6: U-shaped loop with recurrent branch was observed in $2.5 \%$ of cases (Fig. 4f, Table II). This variation is unique to the present study and presented with a proximal and distal LTA which both coursed laterally to the level of the base of the $5^{\text {th }}$ metatarsal where they joined to form a loop and gave rise to the $2^{\text {nd }}, 3^{\text {rd }}$ and $4^{\text {th }}$ DMA. Additionally, a recurrent branch was found proximally joining the two LTA. The recurrent branch was not previously recorded. This has a profound surgical implication as the knowledge of this additional branch may aid surgeon to prevent iatrogenic injury to the vascular supply of the foot. Additionally, the presence of the recurrent branch may improve the viability of the DPA flap in cases of other arterial variations of the DPA, as it may aid to the vascularity of the flap.

The morphological parameters investigated in this study (course, origin and branching pattern), were analysed to determine if a correlation with laterality existed. Statistical analysis revealed no significant $p$ values. This may be attributed to a low sample size and unequal numbers of left and right feet. In addition, the present study was unable to warrant bilateral equivalence due to the low numbers of specimens available for dissection.

For future investigation into the anatomy of the DPA and to determine a correlation with laterality, it is suggested that bilateral equivalence is ensured and that cadaveric records of all specimens are present and available for analysis with regard to age, sex and population group.

\section{CONCLUSION}

This study described the anatomy of the DPA by outlining its course, origin and branching pattern. Variations in these parameters were recorded, with the prevalence of branching patterns Types 1 to 6 . The addition of the Type 6 branching pattern is unique to this study and was not previously recorded. Knowledge of these variations is of prime importance to clinicians in the diagnosis of peripheral arterial disease, to surgeons with regard to reconstructive DPA flap surgery as well as to angiographers to ensure the accurate interpretation of imaging studies.
LUCKRAJH, J. S.; LAZARUS, L.; NAIDOO, N.; RENNIE, C. \& SATYAPAL, K. S. Anatomía de la arteria dorsal del pie. Int. J. Morphol., 36(2):730-732, 2018,

RESUMEN: La arteria dorsal del pie (ADP) es el vaso sanguíneo más grande distal a la articulación del tobillo. Es la continuación de la arteria tibial anterior (ATA) y se extiende a lo largo del dorso del pie hasta el primer espacio metatarsiano. La ADP da lugar a cinco ramas: a. tarsalis medialis, a. tarsalis lateralis, a. arcuata, a. plantaris profunda y aa. metatarsales dorsales. Dado el vasto suministro de sangre proporcionado por la ADP, en la era actual de la cirugía microvascular, la anatomía de la ADP es de creciente interés para los anatomistas, cirujanos y expertos en angiografía. El objetivo de este estudio fue delinear el curso, origen, patrones de ramificación y las posibles variaciones de la ADP. El presente estudio incluyó la disección de cuarenta $(\mathrm{n}=40)$ muestras cadavéricas del miembro inferior (izquierda: 25; derecha: 15). Se estudiaron los patrones de origen, curso y ramificación de la arteria. Estos parámetros morfológicos se analizaron adicionalmente con respecto a la lateralidad para determinar si existía una correlación. Se empleó la prueba Chi-cuadrado de Pearson y se consideró estadísticamente significativo un valor de $\mathrm{p}$ de menos de 0,05. Aunque la ADP estuvo presente en el 97,5\% de los casos, siguió la descripción anatómica estándar en solo el $42,5 \%$ de los casos. La ADP se originó en la arteria fibular en el 5 $\%$ de los casos. En el $25 \%$ de los casos, la ADP se desvió lateralmente. La variación en el patrón de ramificación de la ADP, que se registró en el $50 \%$ de los casos, se clasificó según los tipos 1 a 6 . Los hallazgos de este estudio se correlacionaron estrechamente con la mayoría de los estudios previos. Sin embargo, la incidencia de desviación lateral de la ADP fue mayor en este estudio, así como la incidencia de la variación del tipo 1 en el patrón de ramificación. Además, este estudio propone una nueva variación en el patrón de ramificación que se ha denominado Tipo 6, que muestra una rama recurrente de la variación Tipo 5. La ADP tiene un papel importante en la clínica, ya que el colgajo de la ADP se emplea en cirugías reconstructivas y la circulación periférica se puede evaluar mediante la palpación del pulso de la ADP. Por lo tanto, una comprensión profunda de la anatomía de la ADP es de vital importancia para los podólogos, cirujanos, anatomistas y en la angiografía.

PALABRAS CLAVE: Arteria dorsal del pie; Anatomía arterial; Colgajo dorsal del pie; Pulso dorsal del pie.

\section{REFERENCES}

Awari, P. \& Vatsalaswamy, P. Anatomical variations in dorsalis pedis artery and its branches with clinical correlations. Int. J. Curr. Res., 8(10):406926, 2016.

Cheung, C. C.; Keogh, M. \& Alashkham, A. Variations in origin and course of the dorsalis pedis artery: A case study. Int. J. Anat. Var., 10(1):1-3, 2017.

Chow, L. C.; Napoli, A.; Klein, M. B.; Chang, J. \& Rubin, G. D. Vascular mapping of the leg with multi-detector row CT angiography prior to free-flap transplantation. Radiology, 237(1):353-60, 2005.

El-Saeed, E.; El-Monsif, A.; El-Sayed, M.; Aly, N. \& Gezlan, N. Anatomical study of the dorsalis pedis artery and its surgical importance in 
reconstructive surgery. Alex. Bull., 44(2):557-71, 2008.

Kelikian, A. S. \& Sarrafian, S. K. Sarrafian's Anatomy of the Foot and Ankle: Descriptive, Topographic, Functional. $3^{\text {rd }}$ ed. Philadelphia, Wolters Kluwer Health, 2011.

Khaki, A. A.; Shokouhi, G.; Shoja, M. M.; Farahani, R. M.; Zarrintan, S.; Khaki, A.; Montazam, H.; Tanoomand, A. \& Tubbs, R. S. Ansa cervicalis as a variant of spinal accessory nerve plexus: a case report. Clin. Anat., 19(6):540-3, 2006.

Kulkarni, V. \& Ramesh, B. R. A Morphological study of dorsalis pedis artery and its clinical correlation. J. Pharm. Biol. Sci., 2(3):14-9, 2012.

Kumari, M. \& Bharti, J. P. Anatomic Variations of arteria dorsalis pedis: A cadaveric study on 40 dissected lower limbs with clinical correlations. Int. J. Contemp. Med. Res. 3(6):1575-6, 2016.

Mamatha, Y.; Sunitha, R. \& OmPrakash, K. V. Variation in branching pattern of dorsalis pedis artery. Int. J. Sci. Res., 5(9):1662-4, 2014.

Moore, K. L.; Dalley II, A. F. \& Agur, A. M. R. Clinically Oriented Anatomy. 7th ed. Philadelphia, Wolters Kluwer Health/Lippincott Williams \& Wilkins, 2014.

Mowlavi, A.; Whiteman, J.; Wilhelmi, B. J.; Neumeister, M. W. \& McLafferty, R. Dorsalis pedis arterial pulse: palpation using a bony landmark. Postgrad. Med. J., 78(926):746-7, 2002.

Rajeshwari, M. S.; Roshankumar, B. N. \& Vijayakumar. An anatomical study on dorsalis pedis artery. Int. J. Anat. Res, 1(2):88-92, 2013.

Shetty, S. D.; Nayak, S.; Kumar, N. \& Abhinitha, P. Hypoplastic anterior tibial artery associated with continuation of fibular (peroneal) artery as dorsalis pedis artery. A case report. Int. J. Morphol., 31(1):136-9, 2013.

Standring, S. Gray's Anatomy: The Anatomical Basis of Clinical Practice. $41^{\text {st }}$ ed. New York, Elsevier, 2016.

Tank, P. W. \& Grant, J. C. B. Grant's Dissector. $15^{\text {th }}$ ed. Philadelphia, Wolter Kluwer Health/Lippincott Williams \& Wilkins, 2013.

Vazquez, T.; Rodríguez-Niedenfuhr, M.; Parkin, I.; Viejo, F. \& Sanudo, J. Anatomic study of blood supply of the dorsum of the foot and ankle. Arthroscopy, 22(3):287-90, 2006.

Vengadesan, B. \& Pushpalatha, K. An anatomical study on dorsalis pedis artery. Int. J. Sci. Res., 6(2):147-9, 2017.

Vijayalakshmi, S.; Raghunath, G. \& Shenoy, V. Anatomical study of dorsalis pedis artery and its clinical correlations. J. Clin. Diagn. Res., 5(2):28790, 2011.
Corresponding author:

Dr. L. Lazarus

Department of Clinical Anatomy

School of Laboratory Medicine and Medical Science

College of Health Sciences

University of KwaZulu-Natal

Private Bag X54001

Durban

4000

SOUTHAFRICA

\section{E-mail ramsaroopl@ukzn.ac.za}

Received: 29-10-2017

Accepted: 07-02-2018 